\title{
Fibroblast growth factor 23, iron and inflammation - are they related in early stages of chronic kidney disease?
}

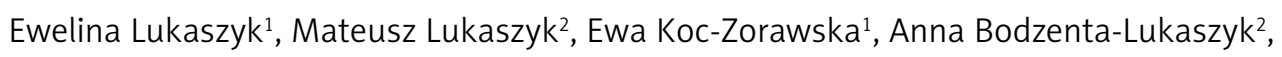
Jolanta Malyszko ${ }^{1}$

\author{
${ }^{1} 2^{\text {nd }}$ Department of Nephrology and Hypertension with Dialysis Unit, \\ Medical University of Bialystok, Bialystok, Poland \\ ${ }^{2}$ Department of Allergy and Internal Medicine, Medical University of Bialystok, \\ Bialystok, Poland
}

Submitted: 16 November 2015

Accepted: 31 December 2015

Arch Med Sci 2017; 13, 4: 845-850

DOI: https://doi.org/10.5114/aoms.2016.58647

Copyright $@ 2016$ Termedia \& Banach

\section{Abstract}

Introduction: Fibroblast growth factor 23 (FGF-23) levels are elevated in impaired renal function. Inflammation and iron are potential regulators of FGF-23. The aim of the study was to evaluate the association between FGF-23 concentration, novel iron status biomarkers and inflammatory parameters among patients with early stages of chronic kidney disease (CKD). Material and methods: The study population included 84 patients with CKD in the early stage. Serum hemoglobin, fibrinogen, creatinine, iron, transferrin saturation and ferritin levels were measured using standard laboratory methods. Commercially available kits were used to measure: intact FGF-23, hepcidin, soluble transferrin receptor (sTfR), interleukin 6 (IL-6) and high-sensitivity C-reactive protein (hsCRP).

Results: In patients with CKD no differences in FGF-23 concentration according to iron status were observed. Lower iron concentration was associated with higher concentrations of hsCRP, IL- 6 and fibrinogen. In univariate and multivariate analysis FGF-23 correlated with fibrinogen $(r=-0.23, p<0.05)$ and eGFR $(r=-0.36, p<0.05)$.

Conclusions: FGF-23 is affected by kidney function and fibrinogen but not iron status parameters in the early stages of CKD. Our data are paving the way for further studies on the role of FGF-23 in iron metabolism, especially in early stages of CKD.

Key words: chronic kidney disease, fibroblast growth factor 23, inflammation, iron.

\author{
Corresponding author: \\ Prof. Jolanta Malyszko \\ $2^{\text {nd }}$ Department \\ of Nephrology \\ and Hypertension \\ with Dialysis Unit \\ Medical University \\ of Bialystok \\ 24a Skłodowskiej-Curie St \\ 15-289 Bialystok, Poland \\ Phone: +48 857409464 \\ E-mail: jolmal@poczta.onet.pl
}

\section{Introduction}

The family of fibroblast growth factors (FGFs) regulates a plethora of developmental processes; the first five subfamilies fall into this category [1]. By contrast, the FGF-19, FGF-21 and FGF-23 subfamily has recently been shown to function in an endocrine manner, dependent on the presence of Klotho proteins in their target tissues, to regulate bile acid, cholesterol, glucose, vitamin D and phosphate homeostasis [1, 2]. 
Fibroblast growth factor 23 (FGF-23) is a hormone produced by osteocytes and osteoblasts involved in phosphate and active vitamin D homeostasis. FGF-23 acts through two main mechanisms - it inhibits absorption of phosphate in the intestine by reducing active vitamin $D$ synthesis and decreases the phosphate reabsorption in renal proximal tubules [3]. It is present in three major forms: biologically active intact FGF-23 (iFGF-23), the inactive C-terminal (CFGF-23) and the N-terminal fragment. Chronic kidney disease (CKD) is the principal example of secondary FGF-23 excess in response to hyperphosphatemia [4]. However, whether the increased FGF-23 levels in chronic kidney disease are beneficial or harmful is still a matter of debate [5]. CKD is also a risk factor for cardiovascular disease [6], and it has been reported that an increased level of FGF-23 is associated with progression of CKD, higher risk of cardiovascular complications (vascular dysfunction, left ventricular hypertrophy) and mortality [7, 8]. However, regulation of FGF-23 in CKD remains unclear, particularly in the early stages of chronic kidney disease, where FGF-23 concentration is elevated before the increase in serum phosphate [9]. Munoz Mendoza et al. reported that FGF-23 concentration is independently associated with inflammation in patients with CKD [10]. In contrast, Braithwaite et al. [11] did not find correlations between FGF-23 and inflammatory parameters. FGF-23 production in osteocytes also increases in response to iron deficiency; however, in healthy individuals it is accompanied by intensification of proteolytic cleavage, resulting in the increase of inactive FGF-23 forms (detectable as cFGF-23). In patients with CKD proteolytic cleavage of FGF-23 is impaired; therefore in the state of iron deficiency commonly accompanying CKD both forms of FGF23 may be detectable (iFGF-23 and cFGF-23) [12]. Iron homeostasis is also affected by inflammation; hence FGF-23 regulation in CKD may be the result of correlations between kidney function, iron status and inflammation.

Considering the high prevalence of iron deficiency, inflammation and FGF-23 excess in patients with CKD, we investigated the associations between biologically active FGF-23 concentration, novel iron status parameters including hepcidin and inflammatory parameters in early stages of this disease. This relation might serve as an explanation of increased FGF-23 levels in early stages of CKD as well as a predictor of adverse cardiovascular outcomes.

\section{Material and methods}

A total of 84 patients with an established diagnosis of CKD and 23 healthy controls were enrolled in the study. Chronic kidney disease was defined as either an estimated glomerular filtration rate
(eGFR) $\leq 60 / \mathrm{ml} / \mathrm{min} / 1.73 \mathrm{~m}^{2}$ or presence of hematuria or proteinuria for $\geq 3$ months. Exclusion criteria included: acute inflammation or thrombosis; active oncological disease; acute cardiovascular complication (including uncontrolled hypertension, acute coronary syndrome, acute heart failure); any anemia and/or iron deficiency treatment; blood transfusions within 3 months preceding the study; immunosuppressive therapy. All patients were at least 18 years of age. The study protocol has been approved by the local Medical University Ethics Committee. All patients were fully informed about the study and gave their consent.

Medical history (including demographic characteristics as well as current pharmacotherapy) and blood samples were collected in all subjects at the time of enrolment in the morning after an overnight rest. Hematological measurements were made using fresh venous blood with EDTA and clotted blood. The plasma and serum were centrifuging and frozen at $-70^{\circ} \mathrm{C}$ until further laboratory analysis. All laboratory analyses were performed in patients with CKD. In healthy volunteers several significant parameters were measured.

Serum hemoglobin, fibrinogen, creatinine, iron, total iron binding capacity (TIBC) and ferritin levels were measured using standard laboratory methods (automated system - Architect, Abbot Diagnostics, USA) in a certified local central laboratory. Transferrin saturation (TSAT) was calculated as the ratio of serum iron and TIBC and expressed as a percentage. Estimated glomerular filtration rate was calculated from the Chronic Kidney Disease Epidemiology Collaboration (CKD-EPI) equation according to the latest KDIGO guidelines [13].

Commercially available kits were used to measure: FGF-23 (Human FGF-23 Intact ELISA Kit, Immunotopics, Inc. San Clemente, USA), hepcidin-25 (EIA Kit, Peninsula Laboratories, LLC, Bachem Group, USA), soluble transferrin receptor (sTfR) (Quantikine IVD ELISA Kit, R\&D Systems, Minneapolis, USA), interleukin 6 (IL-6) (Quantikine ELISA Kit, R\&D Systems, Minneapolis, USA) and high sensitivity C-reactive protein (hsCRP) (CRP Elisa Kit- LDN Labor Diagnostika Nord GmbH\&Co KG, Nordhorn, Germany).

\section{Statistical analysis}

Data with normal distribution were reported as mean \pm standard deviation, and non-normally distributed data were reported as median and interquartile range. Normal distribution of variables was analyzed using the Shapiro-Wilk W test. Variables with skewed distribution were log (In)-transformed before further statistical analysis (FGF-23, hsCRP, IL-6, hepcidin, sTfR).

For comparison of differences between groups, analysis of variance (ANOVA) (with post hoc Tukey test for unequal groups) or Kruskal-Wallis test was 
used. Analyses of the correlation of each parameter were performed using Pearson or Spearman correlation coefficients. Multiple regression analysis was used to determine independent factors affecting dependent variables. $P$-values of less than 0.05 were considered to represent statistical significance. All statistical analyses were performed using Statistica 10.0 (StatSoft) computer software.

\section{Results}

The average age of CKD patients was 69 years (Table I). The most common comorbidities were hypertension and diabetes $(60 \%$ and $24 \%$ respectively).

Statistical analysis was performed regarding three tertiles of iron values (lower 16-54, middle 55-91 and upper 92-172 $\mu \mathrm{g} / \mathrm{dl}$ ) - Table II.

As expected, patients with established diagnosis of CKD had significantly higher levels of iFGF-23 and lower concentration of iron than healthy controls. Lower concentration of iron was associated with higher concentrations of inflammatory parameters such as hsCRP, IL-6, and fibrinogen.

Pearson and Spearman correlations between investigated parameters in patients with early stages of CKD are presented in Table III.
In patients with CKD iFGF-23 presented a negative correlation with fibrinogen $(r=-0.23, p<$ $0.05)$ and eGFR $(r=-0.36, p<0.05)$. The correlation with fibrinogen was particularly marked in stage $2(r=-0.4, p<0.05$, Figure 1$)$.

There were no correlations between iFGF-23 and iron status parameters. Serum iron was correlated with IL-6, hsCRP and fibrinogen.

In multivariate analysis fibrinogen and GFR were found to be predictors of logFGF-23 $(\beta=-0.32$, $p=0.003 ; \beta=-0.39, p<0.001$ respectively) explaining $22 \%$ of iFGF-23 variation in patients with early stages of CKD.

Moreover, we performed regression analysis with iron as the dependent variable and log hsCRP, log hepcidin, log sTfR, log IL-6, log ferritin, and fibrinogen as possible predictor variables. In this analysis log ferritin and log hepcidin were found to be predictors of iron $(\beta=0.22, p=0.02 ; \beta=0.28$, $p=0.03$ respectively) explaining $43 \%$ of iron variation in our studied population.

\section{Discussion}

The results presented in this paper indicate that iFGF-23 level was not related to iron status, but was inversely associated with one of the in-

Table I. Clinical and laboratory characteristics of study participants.

\begin{tabular}{|c|c|c|c|}
\hline Parameter & $\begin{array}{c}\text { CKD } \\
(n=84)\end{array}$ & $\begin{array}{l}\text { Control } \\
(n=23)\end{array}$ & $P$-value \\
\hline Age [years] & $69 \pm 12$ & $52 \pm 9$ & $<0.001$ \\
\hline Female/male (\%) & $59 / 25(70 / 30)$ & $15 / 8(65 / 35)$ & \\
\hline $\mathrm{eGFR}\left[\mathrm{ml} / \mathrm{min} / 1.73 \mathrm{~m}^{2}\right]$ & $67.7 \pm 16$ & $98.1 \pm 16$ & $<0.001$ \\
\hline G2 (eGFR 60-89 ml/min/1.73 m²) & $n=56$ & & \\
\hline G3 (eGFR 30-59 ml/min/1.73 m²) & $n=28$ & & \\
\hline \multicolumn{2}{|l|}{ Etiology of kidney disease (\%): } & & \\
\hline Diabetes & 24 & & \\
\hline Hypertension & 60 & & \\
\hline Other & 16 & & \\
\hline \multicolumn{4}{|l|}{ Laboratory variables: } \\
\hline FGF-23 [pg/ml] & $46(32-60)$ & $13.5(11-17), n=21$ & $<0.001$ \\
\hline $\operatorname{Iron}[\mu \mathrm{g} / \mathrm{dl}]$ & $76.8 \pm 36$ & $95.7 \pm 25$ & 0.02 \\
\hline TSAT (\%) & $28.2 \pm 13$ & $29.1 \pm 7$ & 0.7 \\
\hline $\mathrm{WBC}\left[\times 10^{3} / \mu \mathrm{l}\right]$ & $7.6 \pm 2$ & $5.6 \pm 2$ & $<0.001$ \\
\hline Hemoglobin [g/dl] & $13 \pm 2$ & $14 \pm 1$ & 0.1 \\
\hline Ferritin $[\mathrm{ng} / \mathrm{ml}]$ & $\begin{array}{c}142(90-233) \\
n=82\end{array}$ & $104(61-159)$ & 0.03 \\
\hline sTfR [nmol/l] & $18(14-23)$ & $10(8-11)$ & $<0.001$ \\
\hline
\end{tabular}

Results are presented as mean \pm standard deviation or median (interquartile range). eGFR - estimated glomerular filtration rate, FGF-23 - fibroblast growth factor 23, sTfR - soluble transferrin receptor, TSAT - transferrin saturation, WBC - white blood count. 
Table II. The comparison of subgroups according to iron tertiles

\begin{tabular}{|c|c|c|c|c|}
\hline Tertiles & $\begin{array}{l}\text { Lower }(16-54 \mu \mathrm{g} / \mathrm{dl}) \\
\qquad n=28\end{array}$ & $\begin{array}{c}\text { Middle }(55-91 \mu \mathrm{g} / \mathrm{dl}) \\
\quad n=28\end{array}$ & $\begin{array}{c}\text { Upper }(92-172 \mu \mathrm{g} / \mathrm{dl}) \\
n=28\end{array}$ & $P$-value \\
\hline iFGF-23 [pg/ml] & $45.5(30-64)$ & $41(34-58)$ & $50(33-58)$ & 0.6 \\
\hline $\mathrm{hsCRP}[\mathrm{mg} / \mathrm{l}]$ & $16(5-25)$ & $6(2-13)$ & $4(1-7)$ & 0.003 \\
\hline Hepcidin [ng/ml] & $25.6(3-52)$ & $42(28-67)$ & $35.1(24-51)$ & 0.03 \\
\hline Ferritin $[\mathrm{ng} / \mathrm{ml}]$ & $98.5(50-223)$ & $163(104-231)$ & $161.7(105-260)$ & 0.06 \\
\hline $\mathrm{sTfR}[\mathrm{nmol} / \mathrm{l}]$ & $22.6(3-52)$ & $18(16-20)$ & $16.7(13-19)$ & 0.02 \\
\hline IL-6 [pg/ml] & $2.7(0.6-7)$ & $2.8(0.4-6)$ & $0.5(0.2-3.4)$ & 0.04 \\
\hline Fibrinogen [mg/dl] & $441 \pm 111$ & $421 \pm 95$ & $359 \pm 68$ & 0.007 \\
\hline $\mathrm{eGFR}\left[\mathrm{ml} / \mathrm{min} / 1.73 \mathrm{~m}^{2}\right]$ & $66 \pm 16$ & $70 \pm 16$ & $67 \pm 17$ & 0.7 \\
\hline WBC $\left[\times 10^{3} / \mu l\right]$ & $8 \pm 2.3$ & $7.3 \pm 2.2$ & $7.6 \pm 2.1$ & 0.5 \\
\hline $\mathrm{Hb}[\mathrm{g} / \mathrm{dl}]$ & $12.3 \pm 2.2$ & $13.1 \pm 2$ & $14.3 \pm 2$ & 0.001 \\
\hline $\operatorname{RBC}\left[\times 10^{6} / \mu \mathrm{l}\right]$ & $4.4 \pm 0.7$ & $4.4 \pm 0.6$ & $4.7 \pm 0.7$ & 0.1 \\
\hline
\end{tabular}

Results are presented as mean \pm standard deviation or median (interquartile range). eGFR - estimated glomerular filtration rate, FGF-23 - fibroblast growth factor $23, \mathrm{Hb}$ - hemoglobin, hSCRP - high-sensitivity C-reactive protein, IL-6 - interleukin 6, RBC - red blood count, STfR - soluble transferrin receptor, WBC - white blood count.

Table III. Correlations coefficients between FGF-23, iron and inflammatory parameters in patients with CKD

\begin{tabular}{|c|c|c|c|c|c|c|c|c|c|}
\hline & $\begin{array}{l}\text { iFGF-23 } \\
{[\mathrm{pg} / \mathrm{ml}]}\end{array}$ & $\begin{array}{l}\text { hsCRP } \\
{[\mathrm{mg} / \mathrm{ll}]}\end{array}$ & $\begin{array}{c}\text { Hepcidin } \\
{[\mathrm{ng} / \mathrm{ml}]}\end{array}$ & $\begin{array}{c}\text { sTfR } \\
{[\mathrm{nmol} / \mathrm{l}]}\end{array}$ & $\begin{array}{c}\text { Iron } \\
{[\mu \mathrm{g} / \mathrm{dl}]}\end{array}$ & $\begin{array}{l}\text { Ferritin } \\
{[\mathrm{ng} / \mathrm{ml}]}\end{array}$ & $\begin{array}{c}\text { Fibri- } \\
\text { nogen } \\
\text { [mg/dl] }\end{array}$ & $\begin{array}{c}\text { eGFR } \\
{[\mathrm{ml} / \mathrm{min} /} \\
\left.1.73 \mathrm{~m}^{2}\right]\end{array}$ & $\begin{array}{c}\mathrm{IL}-6 \\
{[\mathrm{pg} / \mathrm{ml}]}\end{array}$ \\
\hline $\begin{array}{l}\text { iFGF-23 } \\
{[\mathrm{pg} / \mathrm{ml}]}\end{array}$ & $x$ & -0.02 & -0.05 & 0.1 & 0.09 & -0.04 & $-0.23^{\star}$ & $-0.36^{\star}$ & 0.2 \\
\hline $\begin{array}{l}\text { hsCRP } \\
{[\mathrm{mg} / \mathrm{l}]}\end{array}$ & & $x$ & $0.26^{*}$ & 0.06 & $-0.42^{*}$ & $0.29^{*}$ & $0.69^{*}$ & -0.16 & $0.45^{\star}$ \\
\hline $\begin{array}{l}\text { Hepcidin } \\
{[\mathrm{ng} / \mathrm{ml}]}\end{array}$ & & & $x$ & $0.36^{*}$ & 0.19 & $0.68^{*}$ & 0.21 & -0.13 & $0.28^{*}$ \\
\hline $\begin{array}{l}\text { sTfR } \\
{[\mathrm{nmol} / \mathrm{l}]}\end{array}$ & & & & $x$ & $-0.36^{*}$ & $-0.37^{\star}$ & 0.04 & -0.08 & 0.12 \\
\hline $\begin{array}{l}\text { Iron } \\
{[\mu \mathrm{g} / \mathrm{dl}]}\end{array}$ & & & & & $x$ & $0.27^{*}$ & $-0.36^{\star}$ & 0.07 & $-0.28^{*}$ \\
\hline $\begin{array}{l}\text { Ferritin } \\
{[\mathrm{ng} / \mathrm{ml}]}\end{array}$ & & & & & & $x$ & 0.13 & -0.01 & 0.15 \\
\hline $\begin{array}{l}\text { Fibrinogen } \\
{[\mathrm{mg} / \mathrm{dl}]}\end{array}$ & & & & & & & $x$ & -0.04 & $0.23^{*}$ \\
\hline $\begin{array}{l}\text { eGFR } \\
{[\mathrm{ml} / \mathrm{min} /} \\
\left.1.73 \mathrm{~m}^{2}\right]\end{array}$ & & & & & & & & $x$ & $-0.35^{*}$ \\
\hline $\begin{array}{l}\text { IL-6 } \\
{[\mathrm{pg} / \mathrm{ml}]}\end{array}$ & & & & & & & & & $x$ \\
\hline
\end{tabular}

eGFR - estimated glomerular filtration rate, FGF-23 - fibroblast growth factor 23, hSCRP - high-sensitivity C-reactive protein, IL-6 - interleukin 6, sTfR - soluble transferrin receptor, WBC - white blood count. *Statistically significant data $(p<0.05)$.

flammatory parameters, i.e. fibrinogen, in patients with early stages of CKD. Serum iron was correlated with inflammatory parameters in our studied population.

Current studies concerning FGF-23 and iron status are inconsistent. In wild type mice iron defi- ciency increases FGF-23 expression [14]. A similar observation was made in healthy volunteers [15]. In this population Imel et al. [15] observed the association of low serum iron levels and elevated cFGF-23 in healthy controls with iFGF-23 in the normal range, while in subjects with rickets low se- 
rum iron was associated with an increase in both cFGF-23 and iFGF-23, which results in hypophosphatemia. Autosomal dominant hypophosphatemic rickets (ADHR) is caused by an FGF-23 mutation that renders it resistant to cleavage [3]. Clinical data of early stages of CKD patients showed a significant decrease in CFGF-23 concentrations after iron deficiency anemia treatment with ferric carboxymaltose [16]. In hemodialysis patients, intravenous administration of saccharated ferric oxide increased the levels of iFGF-23 [17]. In contrast, Deger et al. [18] reported a negative correlation between iron administration and iFGF-23 levels in a dialysis population. On the other hand, the results obtained in a recent study by Bożentowicz-Wikarek et al. [19], which included the largest cohort of patients so far (3780 elderly participants), revealed an association between low iron levels and increased cFGF-23 and iFGF-23 concentrations. The mechanism underlying these paradoxical findings remain unexplained. We did not measure cFGF-23 concentration; hence we cannot exclude the impact of iron status on proteolysis of iFGF-23 [8]. However, it can be postulated that iron deficiency does not increase iFGF-23 in healthy subjects, because it is cleaved by furin into smaller fragments, which are then released and can be detected with the C-terminal assay [20].

One of the most common factors influencing iron homeostasis is inflammation, which is present in CKD, especially in end-stage CKD [21]. This is usually the subclinical form of the inflammatory process, which may be the consequence of decreased uremic clearance that may result in several uremia-related immune dysfunctions, such as neutrophil apoptosis [22]. Inflammation and the iron axis have been intensively studied in the population of hemodialyzed patients [23, 24]. IL-6, hsCRP and fibrinogen significantly correlated with iron in our studied population, which is in line with previous research $[23,24]$.

There are contradictory results regarding inflammation and FGF-23 in previous studies. Braithwaite et al. [11] found no correlation between FGF-23 and inflammation defined as elevated $\mathrm{C}$-reactive protein (CRP) in children with high prevalence of iron deficiency and inflammation. On the other hand, in a large population of patients with CKD, Munoz Mendoza et al. [10] demonstrated that increased FGF-23 concentrations are independently associated with higher levels of inflammatory parameters including CRP, interleukin 6 (IL-6), TNF- $\alpha$ and fibrinogen. These results are in contrast to our findings, where higher levels of iFGF-23 are associated with lower levels of fibrinogen. However, in both previously mentioned studies only cFGF-23 was investigated. Hence, proteolytic cleavage may also play an important role in the inflammatory state, not only in iron deficiency.

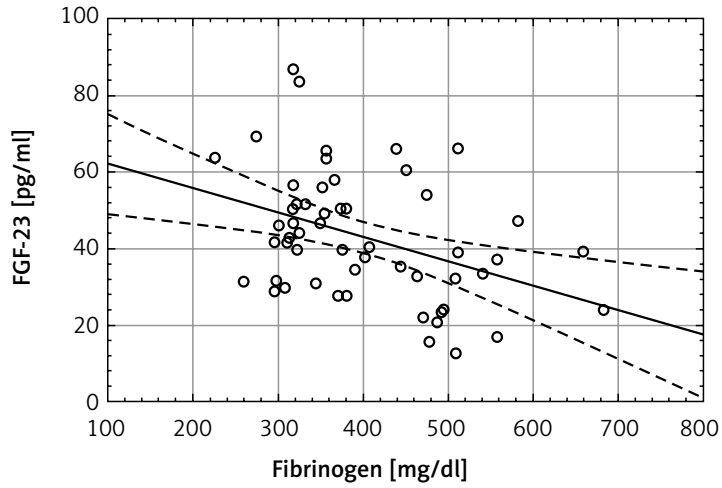

Figure 1. Correlation between iFGF-23 and fibrinogen in patients with CKD, stage $2(r=-0.4, p<0.05)$

We would like to stress the novel conceptual approach to search for the possible associations between iron status, mineral metabolism and common comorbidities in a fairly moderate sample size of CKD patients as for a pilot study. As relations between the mineral axis and FGF-23 have been extensively studied, we focused on different aspects and looked for iron and inflammatory parameters in relation to FGF-23 in the early stages of CKD.

There is mounting evidence suggesting that micronutrient abnormalities, including those related to the bone/mineral axis, iron, gut physiology, and systemic inflammation, play a major role in accelerating CKD and cardiovascular diseases [25].

In the $21^{\text {st }}$ century the discovery of FGF- 23 has improved our knowledge about mineral homeostasis in both health and disease. However, we are just beginning to unravel the complex role of FGF-23, not only in bone biology, but also in iron metabolism, and our data are paving the way for further studies on the role of FGF-23 in cardiorenal syndrome or cardiorenal anemia syndrome, in particular in the early stages of CKD. In addition, given its involvement in the pathogenesis of human disease, FGF-23 holds promise as a therapeutic target, and a range of studies have confirmed its potential [1]. However, the contribution of FGF-23 to chronic kidney disease is still far from clear, but this ligand may also have pharmacological significance in this context [26].

\section{Conflict of interest}

The authors declare no conflict of interest.

\section{References}

1. Beenken A, Mohammadi M. The FGF family: biology, pathophysiology and therapy. Nat Rev Drug Discov 2009; 8: 235-53.

2. Rysz J, Gluba-Brzózka A, Mikhailidis DP, Banach M. Fibroblast growth factor 19-targeted therapies for the treatment of metabolic disease. Expert Opin Investig Drugs 2015; 24: 603-10. 
3. ADHR Consortium. Autosomal dominant hypophosphataemic rickets is associated with mutations in FGF23. Nat Genet 2000; 26: 345-8.

4. Wolf $M$. Forging forward with 10 burning questions on FGF23 in kidney disease. J Am Soc Nephrol 2010; 21: 1427-35

5. Razzaque MS. Does FGF23 toxicity influence the outcome of chronic kidney disease? Nephrol Dial Transplant 2009; 24: 4-7.

6. Franczyk-Skóra B, Gluba A, Banach M, Rysz J. Treatment of non-ST-elevation myocardial infarction and ST-elevation myocardial infarction in patients with chronic kidney disease. Arch Med Sci 2013; 9: 1019-27.

7. Scialla JJ, Xie H, Rahman $M$, et al. Fibroblast growth factor-23 and cardiovascular events in CKD. J Am Soc Nephrol 2014; 25: 349-60.

8. Ix JH, Katz R, Kestenbaum BR, et al. Fibroblast growth factor-23 and death, heart failure, and cardiovascular events in community-living individuals: CHS (Cardiovascular Health Study). J Am Coll Cardiol 2012; 60: 200-7.

9. Isakova T, Wahl P, Vargas GS, et al. Fibroblast growth factor 23 is elevated before parathyroid hormone and phosphate in chronic kidney disease. Kidney Int 2011; 79: 1370-8.

10. Munoz Mendoza J, Isakova T, Ricardo AC, et al. Chronic Renal Insufficiency Cohort. Fibroblast growth factor 23 and inflammation in CKD. Clin J Am Soc Nephrol 2012; 7: 1155-62.

11. Braithwaite V, Prentice AM, Doherty C, Prentice A FGF23 is correlated with iron status but not with inflammation and decreases after iron supplementation: a supplementation study. Int J Pediatr Endocrinol 2012; 2012: 27.

12. Wolf M, White KE. Coupling fibroblast growth factor 23 production and cleavage: iron deficiency, rickets, and kidney disease. Curr Opin Nephrol Hypertens 2014; 23: 411-9.

13. KDIGO 2012 Clinical Practice Guideline for the Evaluation and Management of Chronic Kidney Disease. Kidney Int Suppl 2013; 3: 1-150.

14. Farrow EG, Yu X, Summers LJ, et al. Iron deficiency drives an autosomal dominant hypophosphatemic rickets (ADHR) phenotype in fibroblast growth factor-23 (Fgf23) knock-in mice. Proc Natl Acad Sci U S A 2011; 108: E1146-55.

15. Imel EA, Peacock M, Gray AK, et al. Iron modifies plasma FGF23 differently in autosomal dominant hypophosphatemic rickets and healthy humans. J Clin Endocrinol Metab 2011; 96: 3541-9.

16. Prats M, Font R, Garcia C, et al. Effect of ferric carboxymaltose on serum phosphate and C-terminal FGF23 levels in non-dialysis chronic kidney disease patients: post-hoc analysis of a prospective study. BMC Nephrology 2013; 14: 167.

17. Takeda $\mathrm{Y}, \mathrm{Komaba} \mathrm{H}$, Goto S, et al. Effect of intravenous saccharated ferric oxide on serum FGF23 and mineral metabolism in hemodialysis patients. Am J Nephrol 2011; 33: 421-6.

18. Deger SM, Erten Y, Pasaoglu OT, et al. The effects of iron on FGF23-mediated Ca-P metabolism in CKD patients. Clin Exp Nephrol 2013; 17: 416-23.

19. Bożentowicz-Wikarek M, Kocełak P, Owczarek A, et al. Plasma fibroblast growth factor 23 concentration and iron status. Does the relationship exist in the elderly population? Clin Biochem 2015; 48: 431-6.

20. Bhattacharyya N, Wiench M, Dumitrescu C, et al. Mechanism of FGF23 processing in fibrous dysplasia. J Bone Miner Res 2012; 27: 1132-41.
21. Rysz J, Banach M, Cialkowska-Rysz A, et al. Blood serum levels of IL-2, IL-6, IL-8, TNF-alpha and IL-1beta in patients on maintenance hemodialysis. Cell Mol Immunol 2006; 3: 151-4.

22. Zahran N, Sayed A, William I, et al. Neutrophil apoptosis: impact of granulocyte macrophage colony stimulating factor on cell survival and viability in chronic kidney disease and hemodialysis patients. Arch Med Sci 2013; 9: 984-9.

23. Małyszko J, Koc-Żórawska E, Levin-laina N, et al. New parameters in iron metabolism and functional iron deficiency in patients on maintenance hemodialysis. Pol Arch Med Wewn 2012; 122: 537-42.

24. Malyszko J, Koc-Zorawska E, Levin-laina N, et al. Iron metabolism in hemodialyzed patients - a story half told? Arch Med Sci 2014; 10: 1117-22.

25. Charytan DM, Fishbane S, Malyszko J, McCullough PA, Goldsmith D. Cardiorenal syndrome and the role of the bone-mineral axis and anemia. Am J Kidney Dis 2015; 66: 196-205.

26. Gluba A, Banach M, Hannam S, Mikhailidis DP, Sakowicz A, Rysz J. The role of Toll-like receptors in renal diseases. Nat Rev Nephrol 2010; 6: 224-35. 